\title{
A ATUAÇ̃̃O DE MULHERES COMO PALHAÇAS: RESISTÊNCIA E SUBVERSÃO
}

\author{
THE PERFORMANCE OF WOMEN AS CLOWNS: RESISTANCE AND SUBVERSION
}

\begin{abstract}
RESUMO
O presente artigo tem por objetivo investigar a atuação de mulheres palhaças, abordando para tanto os aspectos artísticos, políticos, históricos e de pesquisa acadêmica sobre este fenômeno, sobretudo no Brasil contemporâneo. A partir de investigações bibliográficas, exploratórias e experimentais, bem como da descrição e investigação de experiências de palhaças, questiona-se sobre as especificidades deste tipo de atuação que passou por um processo de expansão e visibilidade desde as décadas de 1980 e 1990, ressaltando, ainda, resquícios de sua existência em períodos anteriores.
\end{abstract}

Palavras-chave: Gênero. Mulheres. Palhaçaria. Teatro.Resistência.

\begin{abstract}
The aim of this article is to investigate the role of female clowns, focusing on the artistic, political, historical and academic aspects of this phenomenon, especially in contemporary Brazil. Based on bibliographical, exploratory and experimental investigations, as well as the description and investigation of the experiences of clowns, we question the specificities of this type of action that has undergone a process of expansion and visibility since the 1980 os and 1990s, still, remnants of its existence in previous periods.
\end{abstract}

Keywords: Gender. Women.Clowning.Theatre.Comedy.

\section{Introdução}

A atuação profissional de mulheres como palhaças é um fenômeno observado com expressividade no Brasil contemporâneo. A cada ano somam-se grupos, festivais, encontros, cursos, oficinas e simpósios sobre a atuação de mulheres palhaças, como veremos neste artigo. Acompanhando um movimento global de proliferação de mulheres palhaças, veremos que o Brasil tem um importante papel nesta construção, tendo em vista as proporções do alastramento deste fenômeno a partir das décadas de 1980 e 1990 no país.No intuito de abordar uma temática crescente e ainda pouco conhecida por um público mais amplo, trago questões levantadas a partir de uma pesquisa bibliográfica, exploratória e experimental, além de vivências enquanto mulher que atua como palhaça há mais de dez anos, bem como de experiências vividas por outras palhaças, sobretudo, no contexto brasileiro.

Daiani C. S. R. Brum

Universidade do Estado de Santa Catarina (UDESC) - Brasil. E-mail: daianisevero@gmail.com 
Compreendendo o vínculo indissolúvel entre as práticas das palhaças e composição de saberes acadêmicos e teóricos sobre esta temática, busco aportes na ação palhacesca, de modo que a partir de sua observação, descrição e compreensão se possam vislumbrar as concepções teóricas e metodológicas aqui relacionadas.

Este texto é um resultado parcial de minha pesquisa doutoral, que se encontra em andamento no Programa de Pós-Graduação em Teatro da Universidade do Estado de Santa Catarina (UDESC). A pesquisa é subsidiada pela bolsa do Fundo de Apoio à Pesquisa do Estado de Santa Catarina (FAPESC) e orientada pela Professora Doutora Maria Brígida de Miranda. Na referida pesquisa investigo as possibilidades de diálogo entre dois fenômenos que se desenvolveram, difundiram e popularizaram de modo concomitante no Brasil contemporâneo, são eles: a atuação palhacesca em contextos hospitalares e a atuação de mulheres como palhaças.

Estes campos artísticos e humanos atualmente vêm constituindo epistemologias próprias, e estabelecem intersecções entre o cotidiano e o Teatro. Deste modo, no presente artigo, tenho por objetivo investigar a atuação de mulheres palhaças, abordando para tanto os aspectos artísticos, políticos, históricos e de pesquisa acadêmica sobre este fenômeno, destacando algumas iniciativas sucedidas, sobretudo, no Brasil. Que fatores ocasionaram a tardia expressividade na presençadas mulheres atuando como palhaças, isto é, apenas a partir das décadas de 1980 e 1990 no Brasil? Quais são os avanços obtidos pelas mulheres palhaças até então? Em que contexto as mulheres investigam a comicidade?

Em um intento que, pela analogia dos objetivos, dialoga com a Crítica Literária Feminista, trazer para o centro deste trabalho as existências de mulheres palhaças trata-se de uma atitude metodológica. A Crítica Literária Feminista é uma teoria que a partir da segunda metade do século XX, aponta para duas vertentes, uma que diz respeito ao resgate de trabalhos literários produzidos por mulheres, e outra à releitura de obras literárias a parir de uma perspectiva feminista, buscando destacar a experiência das mulheres e os contornos sociais que modelaram suas linhas de ação. No intuito de investigar as questões colocadas neste trabalho, abordo as duas perspectivas no contexto desta investigação: pelo viés da ação palhacesca, a ser descrita posteriormente; e pela valorização de uma interlocução que se dê, sobretudo, com autoras, pesquisadoras e palhaças.

Valorizar, observar, descrever e buscar a compreensão das experiências de mulheres palhaças, no âmbito metodológico dialoga, ainda, com a Fenomenologia (Merleau-Ponty, 1945; Beauvoir, 1980). Esta orientação metodologica aponta para a existência individual como constituída por acontecimentos e situações históricas em detrimento de causas puramente biológicas e determinantes, de modo que os fatores sociais e signos culturais sejam constantemente apropriados por cada pessoa. Deste modo, trago alguns dados e informações no sentido de contextualizar a atuação das mulheres como palhaças, situando-as temporal e espacialmente no Brasil do final do século XX e início do século XXI. Que fatores impregnam-se em sua existência?

Escritos de autoras como Mariana Junqueira (2012); Melissa Caminha (2015); Maria do Nascimento (2015) e Sarah Monteah (2015) auxiliam nas ideias deste texto, 
na medida em que foram produzidos na área das Artes e somam saberes acadêmicos e experimentais sobre a palhaçaria feita por mulheres. Trago ainda autoras como Jill Dolan (1990); Mary Del Priore (2000); Judith Butler (1990); Brígida de Miranda (2008) e Karla Cordeiro (2017), no sentido de somar perspectivas feministas e de gênero aos fenômenos investigados. No âmbito da historiografia palhacesca e da comicidade, menciono contribuições colocadas pela pesquisadora Alice Viveiros de Castro (2005) e pelo pesquisador Tristan Rémy (1945), além de colocações de Georges Minóis (2003), tidas como controversas. As referências aqui mencionadas foram buscadas em três idiomas (Português, Inglês e Espanhol).

\section{As mulheres palhaças e a subversão: relato (s) de experiência (s)}

Visando evidenciar a ação palhacesca das mulheres como um ato de subversão frente às concepções sociais predominantemente impostas no âmbito da palhaçaria e em outros contextos da sociedade, tragoinicialmente uma citação originalmente publicada na França, no ano de 20oo, pelo autor Georges Minois:

A feminilidade exclui o cômico. Não há mulheres palhaças, não há mulheres bufas. Um rápido exame do mundo dos cômicos profissionais, do show business atual, lhe dá razão. Mesmo vestida de homem, a mulher não é engraçada, ao passo que o homem vestido de mulher faz rir. Só a mulher velha, justamente aquela que perdeu a feminilidade, pode fazer rir. No jogo da sedução, o riso supre a ausência de charme. É comparável ao charme físico: aquele que ri não resiste mais (Minois, 2003: 611).

Esta concepção pode condizer com as expectativas da sociedade patriarcal em relação às mulheres, uma vez que sua função estaria vinculada aos aspectos sedutores da existência, sendo que sua graça, charme e candura não poderiam ser maculados pela comicidade. Buscando romper com as barreiras impostas pelo olhar patriarcal, as mulheres atravessaram e atravessam a história da humanidade promovendo o riso e a resistência por meio da comicidade.

O pesquisador Ronald Raminelli, por exemplo, afirma que as mulheres velhas já foram vistas pelos homens com temor e aversão, em um contexto em que antes que rir-se delas, recriminavam severamente a sua existência: eram tidas como obstáculos à civilização, 'degeneradas'. A partir de um relato sobre o cotidiano das mulheres entre os Tupinambás, composto através de textos dos séculos XVI e XVII, escritos por viajantes que observaram a cultura indígena no Brasil colonial, oautor afirma que:

As velhas índias, portanto, encarnam este estado avançado da decrepitude, ressaltado em seu pendor pelos prazeres da carne. Os 
desvios da sexualidade e o gosto pelo repasto canibal constituem indíciosinegáveis da degeneração. Os homens, por sua vez, foram poupados pelos missionários e viajantes e não eram vistos desta forma. Em relação às representações do masculino, as das velhas receberam uma dupla carga estereotipada: primeiro, por serem mulheres; segundo por suas idades avançadas. Em suma, elas simbolizavam o afastamento das comunidades ameríndias da cristandade e, sobretudo, a inviabilidade de se prosseguir com os trabalhos de catequese e colonização. Esses seres degenerados eram incapazes de participar da nova comunidade que se instaurava no Novo Mundo. A irreversibilidade dos costumes e de sua moral tornava-as um entrave aos avanços da colonização. As velhas de seios caídos personificavam, nessa perspectiva, a resistência indígena contra os empreendimentos coloniais europeus (Raminelli, 2008: 43).

A resistência das mulheres, como exemplificada na citação acima, pode ser transposta para outros contextos da sociedade. Em algumas nações, como é o caso do Brasil, por exemplo, ser mulher é um fato que está particularmente vinculado à resistência. Isto é, no país uma mulher é assassinada a cada duas horas, em média doze mulheres mortas por dia'; uma é estuprada a cada onze minutos²; quinhentos e três são vítimas de agressão no decorrer de cada hora³ . Entre 2014 e 2017, o número de registros de assassinatos de mulheres lésbicas aumentou em $150 \%$, sendo que nos primeiros dois meses de 2018, foram registrados 26 casos de homicídios motivados pela lesbofobia4; Segundo a Organização Não Governamental (ONG) Internacional TransgenderEuropeo, o Brasil é o país no mundo que mais mata mulheres transexuais e travestis. O último relatório da Organização Mundial da Saúde revela que o país ocupa a $7^{\underline{a}}$ posição entre as nações mais violentas para as mulheres, em um total de 83 países. Cotidianamente noticia-se a vida das mulheres: constantemente hipersexualizadas, postas em risco ou interrompidas.

Enquanto mulher, palhaça, periférica, pesquisadora e lésbica, atuo e escrevo a partir do emaranhado de experiências, dos medos e das lutas ancestrais e cotidianas,

\footnotetext{
1 Estudo divulgado pelo Instituto Brasileiro de Geografia e Estatística (IBGE): Estatísticas de Gênero Indicadores sociais das mulheres no Brasil, divulgado em março de 2018. Disponível em: <https://www. ibge.gov.br/estatisticasnovoportal/multidominio/genero/20163-estatisticas-de-genero-indicadoressociais-das-mulheres-no-brasil.html?edicao=20164\&t=0-que-e $>$. Aceso em 31/07/2018.

2 11ํㅡㄹ Anuário Brasileiro de Segurança Pública (2017) do Fórum Brasileiro de Segurança Pública. Disponível em: $<$ http://www.forumseguranca.org.br/wp-content/uploads/2017/12/ANUARIO_11_2017. pdf $>$. Aceso em 31/07/2018.

3 Estudo "Visível e invisível: a vitimização de mulheres no Brasil", encomendado ao Datafolha pelo Fórum Brasileiro de Segurança Pública, 2017. Disponível em <http://www.forumseguranca.org.br/ atividades/visivel-e-invisivel-a-vitimizacao-de-mulheres-no-brasil/>. Aceso em 31/o7/2018.

4 Dossiê Sobre Lesbocídio no Brasil de 2014 até 2017 - Iniciativa do Núcleo de Inclusão Social - NIS e do Nós: dissidências feministas (UFRJ), 2017. Disponível em: <http://www.agenciapatriciagalvao. org.br/dossies/fontes-e-pesquisas/wp-content/uploads/sites/3/2018/o4/Dossi\%C3\%AA-sobrelesboc\% 3 C $\%$ ADdio-no-Brasil.pdf $>$. Aceso em 31/o7/2018.
} 
das resistências, da sobrevivência. Venho buscando estratégias eações que centralizem a atuação de mulheres palhaças nos diversos espaços da sociedade, especialmente os acadêmicos, teatrais e hospitalares. Por meio de minha composição palhacesca em contato com as de outras palhaças, busco romper com a ideia de feminilidade e estereótipos dirigidos à mulher, além de tecer oportunidades para questionar as normas estabelecidas pelo sistema patriarcal, que possui forte influência na sociedade brasileira.

Concordo deste modo, com a colocação da pesquisadora Mariana Junqueira sobre o final do século XX e início do século XXI, ela afirma que:

Muitas das normas de comportamento construídas pelo patriarcado ainda encontram-se profundamente enraizadas em homens e mulheres, devido, principalmente, ao longo período em que estiveram vigentes. $\mathrm{O}$ patriarcado existe, aproximadamente, há três mil anos e a civilização patriarcal construiu imagens femininas como a matrona e a prostituta; a esposa fiel e a adúltera; a santa e a pecadora. A guerreira, a heroína, a inadequada, a palhaça estavam fora do padrão. E qualquer figura que saísse dos limites impostos era passível de recriminação, tanto por parte de homens quanto de mulheres (Junqueira, 2012: 34).

A composição de minha palhaça, a Doutora Brum, me permite olhar para essas questões de modo demasiadamente ingênuo, malicioso em sobre medida, esquivando-me entre as aparências e firmando-me naquilo que não está dito, nas entrelinhas de cada encontro. Busco por repertórios, gestos e figurinos que confundam as espectadoras e os espectadores em relação ao gênero da palhaça, mais pelo desejo de aceitar uma confusão antiga persistente, do que para gerar efeitos cênicos ou reflexões políticas.

Como a pesquisadora Judith Butler (1990) adverte, o pessoal é político. Estes processos não são separados em recipientes distintos ou narrados em desenvolvimento cronológico, estão intrinsecamenteligados e são constituídos simultaneamente. Como palhaça posso propor uma lógica de atuação que promova revisões em estruturas rigidamente delineadas, especialmente as relacionadas ao gênero. Ao atuar como palhaça ponho em visibilidade um movimento interno e íntimo de confusão entre vestimentas masculinas e femininas, entre demonstrar-me feminina ou masculina, aceitando esta fragilidade como algo que possa fortalecer minha performance. Ao aprofundar as investigações sobre um questão pessoal, posso promover relações com as profundidades, intimidades e fragilidades de outras pessoas que vivenciam situações semelhantes, produzindo identificação e também distanciamento por meio do riso.

A fragilidade desencadeada pela não representação unívoca de gênero permite traçar uma relação, por exemplo, com os dados sobre a vida das mulheres lésbicas e travestis no Brasil, apresentados neste artigo, com a colocação de Butler, quando ela 
afirma que "Assim, como estratégia de sobrevivência, o gênero é uma performance com consequências claramente punitivas.”(Butler, 1990: 273). Ao analisar a cultura contemporânea a autora destaca que a discrição na composição do gênero humaniza os indivíduos, sendo que aqueles que não o manifestam em concordância com a normativa heterossexual são passiveis de punições regulares (Butler, 1990).

Estas estratégias e punições foram vivenciadas por mim e por diversas mulheres em espectros anteriores aos da palhaçaria. As agressões físicas, verbais e psicológicas são frequentemente enfrentadas pela comunidade de Lésbicas, Gays, Bissexuais, Transexuais, Travestis (LGBTT), sendo que pelo falta de legislações específicas para criminalizar a homofobia no Brasil, muitas vezes ela não é estaticizada.

No intuito de elaborar propostas de ruptura com a mecânica social punitiva de gênero, Butler sugere:

Minha sugestão é que o corpo se torne seu gênero através de uma série de atos que são renovados, revisados e consolidados ao longo do tempo. A partir de um ponto de vista feminista, pode-se tentar reconceber o corpo de gênero como o legado de atos sedimentados em vez de uma estrutura predeterminada ou excluída, essência ou fato, seja natural, cultural ou linguístico (Butler, 1990: 274) ${ }^{6}$

Esta sugestão é aqui aproximada ao âmbito de atuação da mulher palhaça, uma vez que, através de processos simbióticos entre a arte e a vida, cada palhaça traça realidades que independem das designações ou dos estereótipos, mesmo que para isso tenha que se confrontar com eles, subvertendo-os, tornando-os um pertence seu que é posto em relação com os fatos e pessoas ao redor. De natureza dúbia e lógica própria, a mulher palhaça pode subverter estruturas fixas, burlar a concepção convencional dos fatos, criar vocábulos e conceber gestuais corpóreos.

Para exemplificar essa perspectiva, considero válido trazer o relato de uma cena que criei como palhaça7. A cena apropria-se da estrutura do casamento, porém,transgride sua lógica heteronormativa, propondo a encenação de uma união entre duas mulheres (a palhaça e uma convidada da plateia) e dois homens (dois convidados da plateia).

5 Livrementetraduzido de: "Hence, as strategy of survival, gender is a performancewhit clearly punitive consequences."

6 Livrementetraduzido de: "My suggestion is that the body becomes its gender through a series of acts which are renewed, revise, and consolidated through time. From a feminist point of view, one might try to reconceive the gendered body as the legacyofsedimented acts rather than a predetermined or foreclosed structure, essence or fact, whather natural, cultural, or linguistic."

7 A referida cena faz parte do espetáculo Manicômicas, criado em maio de 2018 pela Cia Lunáticas de Palhaças e dirigido por Karla Concá, do grupo As Marias da Graça (RJ). A cena pode ser assistida na íntegra (entre os 35 e 45 minutos do vídeo) a partir do seguinte link: <https://www.youtube.com/ watch? $=8$ LbwLNplqok $>$. Acessoem $07 / 08 / 2018$. 


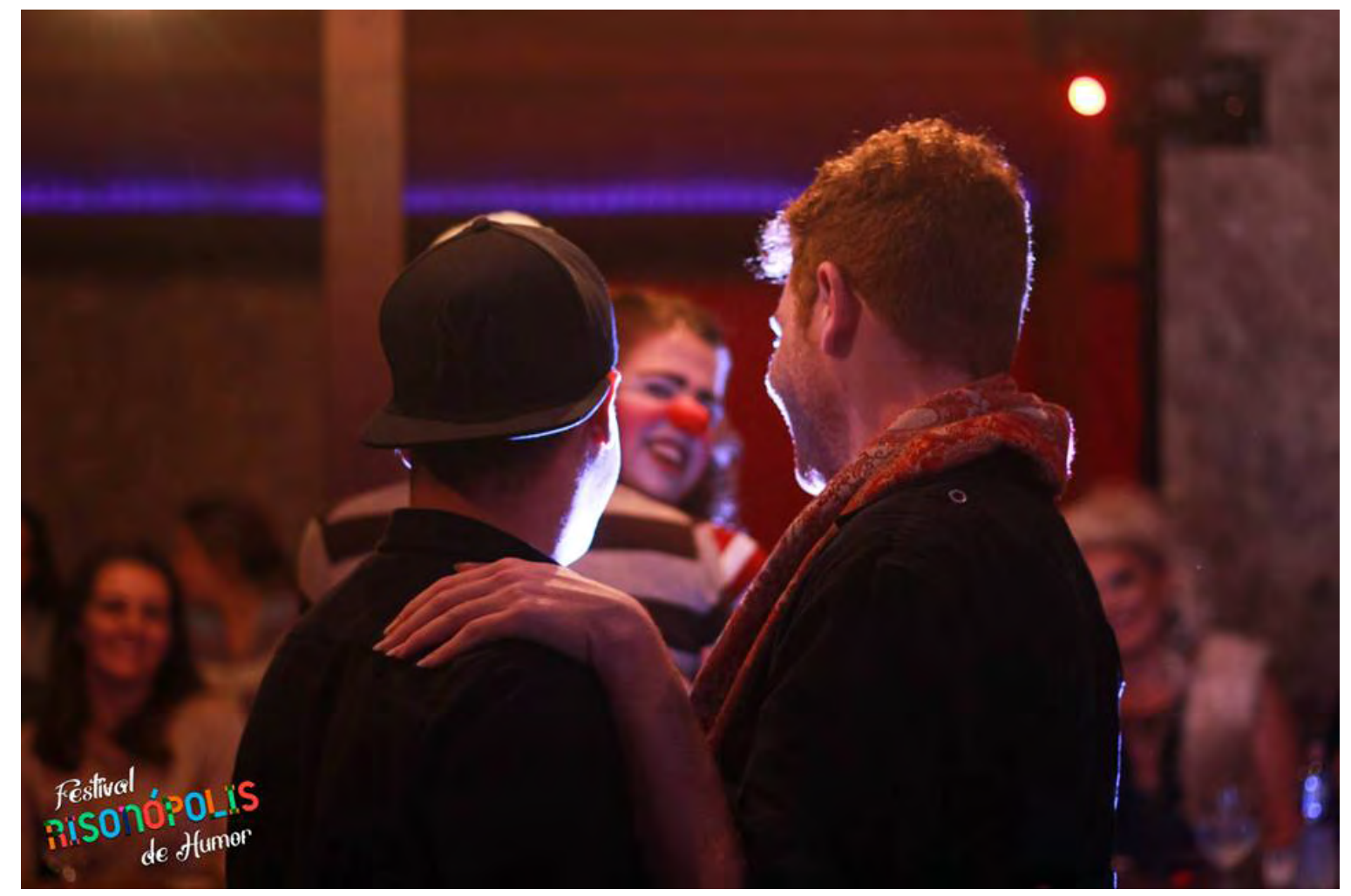

Imagem 1: Festival Risonópolis de Humor. Foto: Thomas Dadan, 2018.

A palhaça Brum entra em cena fazendo um desfile exagerado, inspirado em corporeidades Drag Queens, ampliando os movimentos em diálogo com a música e estabelecendo conexão visual com a plateia, volta desfilando ao fundo do palco, de onde ressurge com três bolinhas de malabarismo, apresenta-as ao público. Faz uma desengonçada apresentação de malabarismo, culpando as bolinhas em caso de queda e injuriando-as (em Alemão), gesto que é seguido de um sorriso simpático ao público, com quem se relaciona carinhosamente.

Em meio a torpe rotina de malabares, a palhaça realiza uma finalização sincronizada com a mudança da música para o estilo romântico. Em um clima de sedução, ela se conecta visualmente com um homem da plateia, que é conduzido para a cena. Dançam tango, jogam bolinhas no fundo da cena. Torna o movimento sincronizado e o clima de romantismo novamente se instaura por meio da música e da ação, Brum dirige-se até outro homem da plateia, em um jogo de paquera, ela volta do público trazendo-o para a cena. A palhaça e os dois homens dançam descontraidamente, jogam bolinhas em trio.

Novamente tornam a música e o movimento sincronizado da palhaça. Nova paixão. Desta vez por uma mulher da plateia, antes de dirigir-se até ela, a palhaça faz um sinal para que os homens aguardem em cena, vai até à mulher, buscando-a para o palco. Dançam ao som de "Besamemucho", romanticamente. Os homens, por sugestão (em alemão) da palhaça, acabam por fazer o mesmo entre si. Dançam 'coladinhos' os casais. No instante seguinte as pessoas são conduzidas para o fundo do palco, onde experimentam uma espécie de coreografia que é interrompida pelo 
som da marcha nupcial. Formam-se dois casais em conformidade com os pares de dança: dois homens, duas mulheres caminham de braços dados até a frente da cena simulando uma espécie de casamento. A palhaça propõe que se beijem na boca.

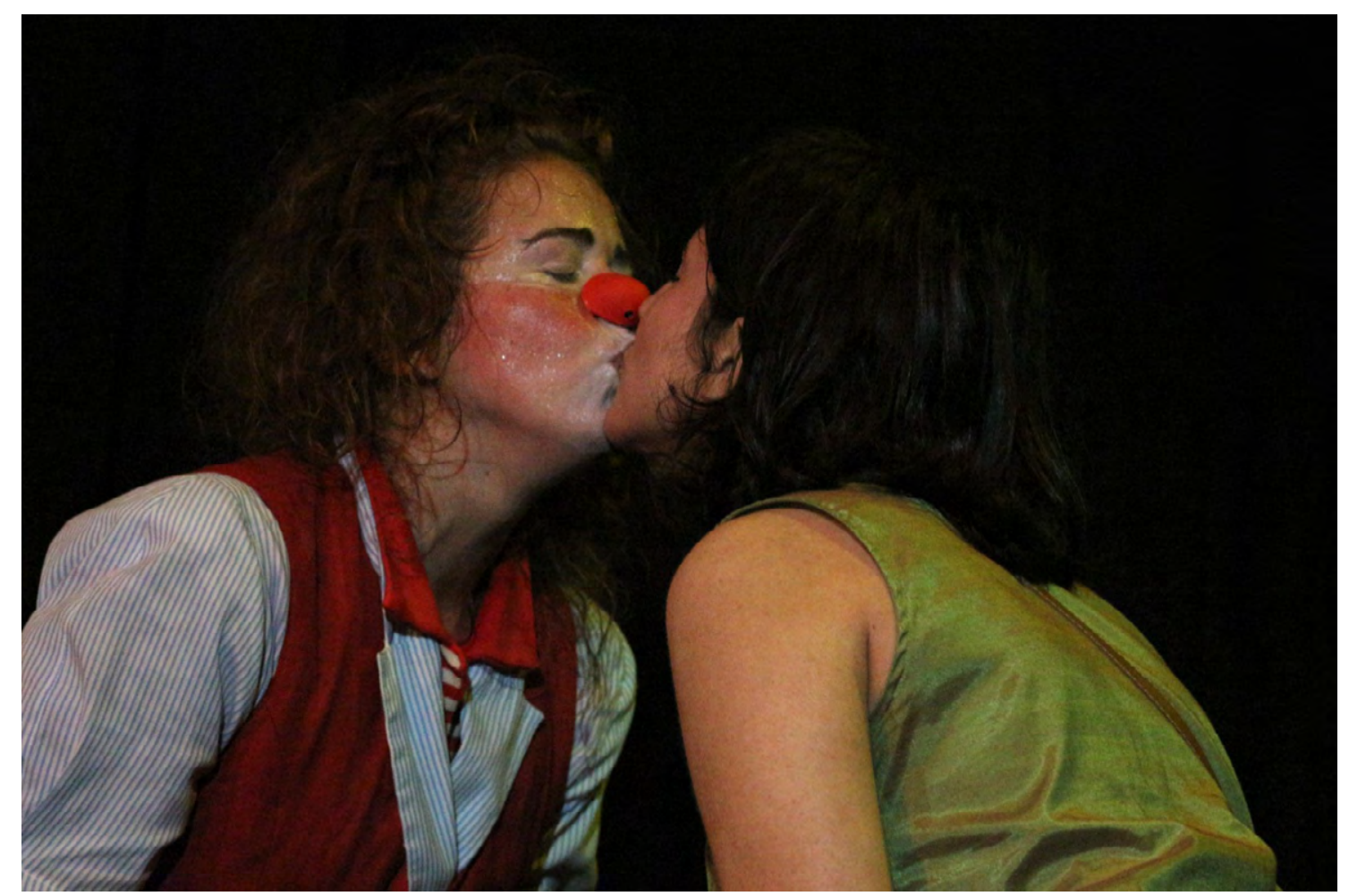

Imagem 2: Arquivo pessoal da autora. Foto: Samira Lemes, 2018.

Até o momento foram realizadas oito apresentações da cena, em espaços culturais de Florianópolis, no Hospital de Custódia e Tratamento Psiquiátrico de Florianópolis (HCTP) e nas programações do $23^{\circ}$ Festival Isnard Azevedo (SC) e do $1^{\circ}$ Cabaré Queerdo $7^{\circ}$ Festival Internacional Esse Monte de Mulher Palhaça (RJ). A cena depende da participação do público e se desenrola conforme as suas reações. Entre os homens, houve aqueles que trocaram um abraço fraterno; os que cordialmente apertaram as mãos; aqueles que encenaram um beijo novelesco, porém, sem tocar os lábios; aqueles que, no momento do beijo, abandonaram a cena afirmando não serem 'veados'. Entre as mulheres, sempre a mesma reação, beijar os lábios da palhaça.

Na cena descrita, a palhaça Brum constrói percepções que extravasam uma forma habitual de estar no mundo. Apropriando-se dos signos gerados pelo casamento e gerando espaços de visibilidade homoafetiva. Buscando brechas para subverter estruturas tradicionais, mesclando elementos do cotidiano na constituição de relações que envolvem um espaço e um tempo diferenciado, a palhaça pode revisitar algumas demarcações impostas pela sociedade, tais como as de gênero, de religião e de orientação sexual, da supervalorização do homem em relação à mulher.

A ação cênica relatada promove uma experiência de desconstrução da estrutura do casamento, historicamente delineado pelos valores da família patriarcal, que como vimos trouxe aspectos perniciosos para a vida das mulheres.

A pesquisadora Jill Dolan, ao referir-se ao realismo no Teatro, coloca que: 
O realismo não é recuperável para as teóricas lésbicas, porque sua ideologia está tão determinada a validar a cultura dominante que a posição lésbica só pode ser contra moralizada ou marginalizada. O tema lésbico mais legível no realismo é o comportamento heterossexual morto ou aquele que imita (Dolan, 1990: 44$)^{8}$.

Deste modo, ao apropriar-se do mote de uma estrutura realista, a representação do casamento, a palhaça toma emprestados alguns marcos realisticamente representados, como o beijo e a marcha nupcial, porém reestruturando sua lógica, onde promove rupturas. A estrutura realista há muito foi apropriada pela atuação palhacesca, onde se valoriza a composição de novas realidades e lógicas próprias a cada conjunção de fatores momentâneos da vida real.

Estas novas realidades palhacescas demonstram-se cada vez mais permeadas pela atuação de mulheres, que buscam rupturas com a cultura dominante: patriarcal, heterormativa, embranquecida e com recorte de classe. Para a pesquisadora Kátia Maria Kásper:

A pesquisa em torno de experimentações envolvendo o que seriam modos femininos de atuar como palhaça tem se ampliado. Partindo da constatação de que o repertório clássico do palhaço tem a ver com o universo masculino, várias mulheres queatuam como palhaças têm buscado uma criação de gags e espetáculos em torno de temáticas femininas, ou de seu universo (Kásper, 2004: 283).

No entanto não é possível afirmar que o repertório clássico da palhaçariaesteja umbilicalmente ligado ao universo masculino, embora a sua interpretação o seja na maioria dos casos observados nesta pesquisa. Portadora de estigmas milenares e contemporaneamente manifestos por meio da palhaçaria, a mulher poderessignificar existências, enquanto se relaciona com as pessoas que vivenciam sua ação cênica. Opor-se aos estereótipos por onde historicamente a palhaçaria se desenvolveu e desenvolve é um desafio cada vez mais presente na vida das mulheres palhaças. A palhaça Val de Carvalho, por exemplo, iniciou um trabalho pioneiro no Brasil de releitura de repertórios clássicos de palhaçaria pelo viés das mulheres. Palhaça circense desde a década de 1990, atualmente Val de Carvalho atua como palhaça na Organização Não Governamental (ONG) Doutores da Alegria e em outros coletivos de Circo e Teatro, dentre eles o Sampalhaças, composto por palhaças de São Paulo.

Promover releituras da realidade patriarcal, assim como desobstruir as fronteiras de gênero são alguns dos caminhos encontrados pelas mulheres na palhaçaria. Em confluência com este pensamento, trago uma colocação da pesquisadora Mariana Rabelo Junqueira, sobre o final do século XX, início do século XXI:

8 Livrementetraduzido de: "Realism is not recuperable for lesbian theorists, because its ideology is so determined to validate dominant culture that the lesbian position can only be moralized against or marginalized. The lesbian subject most readable in realism is enther dead or aping heterosexual behavior." 
A imagem de um ser frágil e necessitado de proteção, sob o domínio dos sentimentos, atuando na intimidade e preso aos cuidados com a prole ganha outros contornos. A mulher talvez ainda não saiba o que quer, mas certamente está buscando um novo discurso e novas regras, não quer mais ser definida pelo homem. É preciso descobrir qual é, então esse novo discurso, definido por esse novo sujeito, para que seja possível descobrir se existe algo de específico, de genuinamente diferente, na maneira de enxergar o mundo e, consequentemente, na maneira de provocar o riso (Junqueira, 2012: 37).

Neste contexto, a palhaça lança olhares para a comicidade do erro, da falha, da derrota, olha para si, sua sexualidade, suas características físicas, seu gênero e sua condição social, de modo que a comicidade seja um dos sinônimos da identidade. Sua dificuldade de inserção nas estruturas de representação masculinizadas na palhaçaria tradicional faz com ela busque novas formas de existir, trazendo novos paradigmas para o repertório palhacesco.

\section{Mulheres palhaças: traços e percursos}

No sentido de investigar alguns traços de percursos trilhados por mulheres palhaças, abro este tópico com uma colocação feita pela pesquisadora Melissa Caminha, segundo a qual: "Se nos fixamos na história das artes, observamos que as mulheres, antes que comediantes, foram bailarinas, cantoras, pintoras, escultoras, escritoras, poetas, cineastas, musicistas, acróbatas e atrizes dramáticas, e comediantes de televisão e teatro antes do que palhaças." (Caminha, 2015: 94). ${ }^{9} \mathrm{O}$ dado trazido pela autora aponta para a especificidade da problemática de gênero no âmbito da palhaçaria, uma vez que denota uma tardia visibilidade das mulheres nessa arte de traços milenares e fortemente delineados nos últimos três séculos (Remy, 1945).

Satirizando aspectos da vida comum as palhaças podem mover reflexões naquelas pessoas que presenciam sua ação, situando-as em um ponto de vista que movimenta as estruturas tradicionalmente impostas, estabelecendo diálogos e modificando-as.

O movimento de visibilidade das mulheres na arte da palhaçaria é ainda acompanhado pelas transformações ocorridas no corpo da mulher, e mesmo a sua negação e ressignificação. Algumas mudanças ocorridas no final do século XX são enunciadas pela pesquisadora Mary Del Priore:

Nos últimos anos, a mulher brasileira viveu diversas transformações físicas. Viu ser introduzida a higiene corporal

9 Livremente traduzido de "Si nos fijamosenla historia de las artes, observamos que lasmujeres antes que comediantes han sido bailarinas, cantantes, pintoras, escultoras, escritoras, poetas, cineastas, músicas, acróbatas y actrices dramáticas. Y, comediantes de televisión y teatro antes que payasas." 
que, alimentada pela revolução microbiológica, transformouse numa radicalização compulsiva e ansiosa. Acompanhou a invenção do batom, em 1925, do desodorante, nos anos 50, cortou os cabelos à lagarçonne, gesto sacrilégio contra bastas cabeleiras do século XIX. O aprofundamento dos decotes levou-a a aderir à depilação. O espartilho, graças ao trabalho feminino nas fabricas, diminui e se transformou em soutien para possibilitar uma maior movimentação dos braços. "Manter a linha" tornou-se um culto, a magreza ativa foi a resposta do século à gordura passiva da belle époque. O jeans colado e a minissaia sucederam, nos anos 6o, ao erotismo da mão na luva e das saias no meio dos tornozelos característico dos anos 90 (Del Priore, 2000: 11-12).

Imersa no contexto social do qual partilha, a mulher palhaça reflete suas implicações ao passo que as tenciona e transforma. Por este percurso adentra-se em uma perspectiva feminista sobre a comicidade feita pelas mulheres, a qual foi sugerida pela pesquisadora Maria Nascimento. Segundo a autora, este entendimento demonstra que:

[...] não há barreiras "naturais" para as mulheres praticarem a palhaçaria. Se houve em algum momento esse tipo de restrição, ela estava pautada na própria ideologia de gênero que restringia o cômico às mulheres para manter privilégios masculinos dentro da sociedade. Nesse sentido, é preciso desconstruir falácias como a da "incapacidade inata" das mulheres em reproduzir um repertório cômico (Nascimento, 2015: 67).

As mulheres percorreram a história manifestando-se teatral e comicamente, sendo quehoje em dia tomam os palcos cômicos da sociedade. Desde a Grécia Antiga até o Período Elisabetano, a presença oficial das mulheres em cena era proibida,porémhá registros de sua persistente presença. Nas origens da mitologia grega, por exemplo, os espetáculos cômicos eram protagonizados pelas mulheres (RAME: 2004).

Não obstante, a atuação de mulheres como criadoras cômicas foi identificada em diversos períodos, como relata a pesquisadora Alice Viveiros de Castro:

Mas há toda outra história que corre além das histórias oficiais. Se prestarmos atenção, vamos encontrar mulheres cômicas recitando poesias na Grécia antiga, dançando na Índia e mandando ver no Circo Romano. Em Bizâncio, a história celebra Teodora, circense de talento ou prostituta leviana, ou talvez uma mulher inteligente que não se curvou aos preconceitos de sua época? Na Idade Média a figura feminina do menestrel errante era chamada spilwin, mas pouco se escreveu sobre ela. As atrizes da Commediedell'arteeram fabulosas cômicas. E sabiam saltar, dançar e cantar muito bem. Mas pouco se fala delas. A história da mulher cômica é cheia de silêncios e falhas (Castro, 2005: 220). 
Desde a época da CommedieDell'Arte, modalidade de teatral de origem popular na Itália do século XV e de grande difusão pela Europa até o século XIX, as mulheres passaram a atuar profissionalmente como atrizes. Segundo a pesquisadora Joice Aglae, a primeira aparição oficial da mulher em cena foi em 1565 (Aglae, 2016).

No século XXI, com o desenvolvimento da pesquisa acadêmica em Artes, observamos a proliferação de investigações teóricas que centralizam a atuação de mulheres palhaças. Em um processo de auto escrita as mulheres produzem trabalhos científicos que visam preencher algumas das lacunas e alguns dos silêncios mencionados por Alice Viveiros de Castro.

Este movimento acompanha o protagonismo na atuação de mulheres palhaças, que começou a firmar-se e ser observado com maior expressividade a partir das décadas de 1980 e 1990. Para a artista, diretora e pesquisadora Karla Concá,

Até os anos 90 era rara a presença de mulheres no universo da palhaçaria. No ambiente circense sua atuação era limitada a números de acrobacia tais como o trapézio, equilíbrio em cavalos ou o contorcionismo que reforçavam os traços de beleza, feminilidade, graça, leveza e perfeição conferidos à mulher. A incidência de mulheres em papéis cômicos circenses, quando observada, tem natureza secundária quando parte do enredo ou estas estão travestidas de homens com o gênero do palhaço mantido em sigilo para o público (Cordeiro, 2017: 01).

O forçoso sigilo pode ter sido fruto das restrições impostas para a mulher pela sociedade, uma vez que o escárnio gerado pela figura palhacesca, bem como a fluidez nas relações com membros exteriores aos da comunidade circense poderiam produzir impressões danosas para a sua imagem social. Condutas permitidas ao homem, quando realizadas por mulheres eram vistas como ilícitas ou pejorativas (Monteah, 2014).

No Brasil, por exemplo, na década de 1940 o Circo Guarany tinha como atração o palhaço Xamego, vivido por Maria Eliza Alves. Outro registro de um palhaço criado por uma mulher no Circo é o palhaço Ferrugem, vivido pela Gena Leão nas décadas de 1980 e 1990. Atualmente, Gena transformou seu palhaço em mulher, a palhaça Ferrugem, que se apresenta com o Circo Grock (RN).

Na década de 1980, com o surgimento da primeira escola de circo do Brasil, a Academia Piolin de Artes Circenses (APAC), os conhecimentos sobre as modalidades circenses passaram a ser transmitidos para pessoas que não eram advindas de famílias circenses. Neste contexto surgiu a palhaça Xaveco Fritza (Val de Carvalho), criada a partir do contato com mestres antigos do circo brasileiro, tais como Picolino, Arrelia, Picoli, Savala, entre outros, e da busca por uma transposição de saberes tradicionalmente representados pelo gênero masculino para seu universo de mulher. 
Até o momento, a partir da literatura consultada e pesquisas realizadas, encontrei o registro das Marias da Graça (RJ) como o grupo mais antigo de mulheres palhaças atuando no Brasil. Ao longo de quase três décadas de existência, as Marias da Graça impulsionaram um movimento de visibilidade das mulheres palhaças no Brasil. O Festival Esse Monte de Mulher Palhaça, por exemplo, criado em 2005 pelo grupo de palhaças foi responsável pela internacionalização das mulheres palhaças do Brasil, uma vez que além de trazer espetáculos estrangeiros de palhaças, trouxe curadoras de Festivais Internacionais, de modo que as palhaças brasileiras começaram a receber convites e maiores oportunidades de trabalho no exterior. ${ }^{10}$

Encontrei, ainda, registros de que na década de 1980 existiam mulheres atuando profissionalmente como palhaças, tais como GardiHutter (Suécia), Hillary Chaplain (Estados Unidos), Ângela de Castro (Brasil/Londres), entre outras.

As mulheres palhaças estiveram presentes desde as primeiras iniciativas de atuaçãopalhacesca nos contextos hospitalares, fenômeno que se profissionalizou a partir de 1986 com a criação do grupo Clown Care, nos Estados Unidos. Dos contextos formativos, inicialmente difundidos por, Michael Chistensen, até a composição e experimentação da palhaçaria nos hospitais observa-se a presença das mulheres palhaças. Caroline Simonds, por exemplo, fundou, em 1991, o gurpo La RireMédicin (França), de palhaças e palhaços que atuam em contextos hospitalares. Atualmente o grupo conta com um elenco de 90 palhaças e palhaços, dos quais 56 são mulheres e 34 são homens ${ }^{11}$.

O século XXI trouxe ainda a proliferação de Encontros e Festivais específicos de mulheres palhaças, revelando a potência deste fenômeno, bem como reconhecendo suas crescentes manifestações, alguns deles são:

"El Festival Internacional de Pallasses de Andorra", que teve início em 2001 e contou com três edições até 2009, em Andorra; o Ciclo de Mulheres Palhaço promovido pela Companhia Teatral Chapitô, em Lisboa-Portugal, com edições anuais de 2008 a 2013; os ciclos "Veryimportantwomen" no espaço "Armazen" em BarcelonaEspanha; "Clownin", festival de mulheres palhaças que ocorre na Áustria bienalmente, de 2006 a 2012; o "Red Pearl Festival" na Suécia e Finlândia, com edições em 2012, 2013, 2014, 2016. [...] No Brasil: o "Festival Internacional de Comicidade Feminina - Esse Monte de Mulher Palhaça”, organizado pela Cia. As Marias da Graça, no Rio de Janeiro, com edições em 2005, 2007, 2009, 2012, 2013, 2016; o "Encontro de Palhaças de Brasília", organizado pela palhaça Manuela Mathusquella, com edições em 2008, 2010, 2012 e 2014; e o Festival Palhaçaria de Recife organizado pela Companhia Animée que ocorreu em 2012 e 2014 (Nascimento, 2015: 51).

10 Esta informação foi obtida em uma entrevista realizada pela autora com a artista Karla Concá, uma das fundadoras do referido Festival. A entrevista será publicada na íntegra em dezembro de 2018 pela Revista Urdimento, do Programa de Pós-Graduação em Teatro da Universidade do Estado de Santa Catarina.

11 Informação disponível em: <https://www.leriremedecin.org/>. Acesso em o1/o8/2018. 
Estes eventos auto-organizativos demonstram a necessidade das mulheres de se conhecerem pessoalmente, partilharem saberes e de promover a articulação de ações conjuntas, traçando os rumos de uma profissão em construção. Fruto destes encontros nasceu a Revista Palhaçaria Feminina. Atualmente em sua quarta edição impressa, a revista é uma iniciativa da palhaça Michele Silveira, do grupo Doutores Risonhos (Chapecó, SC), e reúne artigos de mulheres palhaças e pesquisadoras da palhaçaria.

Agregar mulheres é uma das premissas do movimento feminista, que aqui é compreendido em consonância com pesquisadora Maria Brígida de Miranda, para quem: "[...] o feminismo não é um movimento único e homogêneo, mas um fenômeno com diferentes ideologias e demandas ao longo da história, moldadas por contextos político-sociais específicos." (Miranda, 2008: 134).

No contexto de popularização da atuação profissional de mulheres como palhaças, valorizou-se como atitude política a chamada por uma comicidade feminina, título que se espalhou por revistas, festivais e encontros. No entanto, como coloca a pesquisadora Melissa Caminha, o termo feminino pode excluir algumas mulheres, como aquelas que não se identificam com a ideia/performance de feminilidade, mas que ainda assim se compreendem como mulheres palhaças (Caminha, 2015).

A ideia de feminilidade, cada vez mais esvaziada de significados por meio da mídia e da indústria da beleza, dos cosméticos e instrumentos de estética, équestionada por algumas mulheres, e passa por processos de constante ressignificação. As mulheres como artistas cômicas, podem brincar com estas estruturas, denunciandoas e burlando suas certezas, determinações e imposições, rompendo com as rígidas barreiras comportamentais impostas pelo feminino. Longe de se encerrar, esta discussão busca acompanhar um fluxo que se encontra em constância no Brasil contemporâneo, somando-se ao movimento de registro e difusão da atuação de mulheres palhaças.

De modo que sejam recentes as pesquisas acadêmicas sobre a palhaçaria feita por mulheres, a seguir, trago um registro de algumas de suas produções, encontradas em bibliotecas e bancos digitais de teses e dissertações.

\section{Investigações acadêmicas}

No âmbito desta investigação, observou-se que a partir de 2012 o Brasil passou por um processo de ampliação de pesquisas com este escopo, sendo que foram identificados seis trabalhos que abordam de modo exclusivo o tema da atuação de mulheres como palhaças. É válido destacar que foram encontrados trabalhos onde a palhaçaria feita por mulheres é abordada, ainda, de modo parcial, constando em um ou mais capítulos dos trabalhos.

As cinco dissertações de mestrado e uma tese de doutorado encontradas, que abordam exclusivamente o tema e as suas relações, foram defendidas na área 
das Artes/Artes Cênicas/Teatro, são elas: "Da graça ao riso: contribuições de uma palhaça sobre a palhaçaria”, de Mariana Rabelo Junqueira, dissertação defendida em 2012, na Universidade Federal do Estado do Rio de Janeiro (UNIRIO); "Mulheres palhaças: percursos históricos da palhaçaria feminina no Brasil”, de Sarah Monteath dos Santos, dissertação defendida em 2014, na Universidade Estadual do Estado de São Paulo (UNESP); "Palhaçaria feminina na Amazônia brasileira: uma cartografia de subversões poéticas e cômicas”, de Andréa Bentes Flores, dissertação defendida em 2014 na Universidade Federal do Pará (UFPA); "Comicidade feminina: as possibilidades de construção do cômico no trabalho de mulheres palhaças”, de Elaine Cristina Maia Nascimento, dissertação defendida em 2014 na Universidade Federal da Bahia (UFBA); "Olha a palhaça no meio da praça: LilyCurcio, Lilian Moraes, questões de gênero, comicidade e muito mais!" Maria Silvia do Nascimento, dissertação defendida em 2017 na Universidade Estadual do Estado de São Paulo (UNESP) e a Tese de Doutorado "Payasas: historias, cuerpos y formas de representar la comicidade desde uma perspectiva de género", defendida pela cearense Melissa Lima Caminha, em 2015 na Facultad de Bellas Artes de Barcelona, da Universidad de Barcelona.

$\mathrm{O}$ crescente contingente de pesquisas acadêmicas revela o quão recente e específica é a pesquisa nas Universidades sobre a atuação de mulheres como palhaças. Fortemente influenciadas pelo fazer artístico das mulheres palhaças e seus encontros e festivais, os percursos das pesquisas acadêmicas podem valorizar, registrar e difundir saberes sobre esta modalidade de atuação e de resistência.

\section{Considerações finais}

Ao propor uma investigação sobre a atuação de mulheres como palhaças, bem como de alguns dos aspectos artísticos, políticos, históricos e de pesquisa acadêmica sobre este fenômeno, sobretudo no Brasil contemporâneo, pude perceber que este é um campo de longa extensão, de múltiplos questionamentos e espaços em aberto. Estes espaços ramificam-se pela sociedade, gerando novas percepções sobre a palhaçaria e sobre a vida das mulheres.

Como colocado neste artigo, observou-se que a partir das décadas de 1980 e 1990 se iniciou um movimento global de atuação de mulheres como palhaças, que, no Brasil, culminou em um fenômeno que abalou as próprias estruturas da palhaçaria. As mulheres palhaças fazem-se cada vez mais presentes no cenário artístico, não estando restritas ao campo da sexualidade, de modo que soe longínqua a afirmação de que as mulheres possuem uma falta de aptidão inata para a comicidade. Os avanços visíveis no cenário artístico, que a cada ano é tomado por encontros, espetáculos e grupos de mulheres palhaças, bem como a diversidade dos trabalhos demonstra especificamente o oposto. 
Além de espaço para suas investigações, as mulheres palhaças alcançaram inúmeros avanços em termos profissionais, artísticos, políticos, históricos e de pesquisas acadêmicas, que como aqui demonstrado, constam crescente evolução. Atualmente questionam-se os significados, embora ainda estejam impregnadas no mercado artístico e na sociedade brasileira, das diferenciações entre o trabalho de homens e mulheres.

Nos grandes festivais de Circo e Teatro, ainda é ínfima a participação das mulheres como diretoras ou dramaturgas, por exemplo. Daí explica-se a difusão de encontros e festivais exclusivos de mulheres, onde elas geram oportunidades de trabalho, renda e visibilidade entre si.

Por outro lado, a produção palhacesca atual demonstra a necessidade e busca dos homens pela revisão de uma dramaturgia de piadas tradicionalmente machistas e contrastantes com a recepção de um público cada vez mais diligente. Para as mulheres este fato figura enquanto grande avanço.

Trabalhando profissionalmente como palhaças as mulheres podem romper barreiras e estigmas, uma vez que seu olhar torpe é treinado para desestruturar compreensões cotidianas, criar novas versões sobre os fatos. Em processo de expansão, esta é uma discussão que a cada dia se renova, a partir de publicações, dossiês e investigações, que se somam a um fluxo contínuo.

\section{$172 \quad$ Referências}

BEAUVOIR, Simone. (1980). O Segundo sexo - fatos e mitos. 4a edição. São Paulo: Difusão Européia do Livro. (Texto originalmente publicado em 1949).

BRONDANI, JoyceAglae. (2016). "A Máscara e a Sombra: L'Arte Della Cortigiana". RevistaRepertório, n. 26, 2: p.151-16o, fev-mar.

BUTLER, Judith. (1990). "Performative Acts and Gender Constitution: an essay in Phenomenology and Feminist Theory." In: In CASE, Sue-Ellen. Performing Feminisms: Feminist Critical Theory and Theatre.za edição.United States: The Johns Hopkins University Press. p. 170-182.

CAMINHA, Melissa. (2015). Payasas: historias, cuerpos y formas de representar la comicidade desde una perspectiva de género. Tesis (Doctoradoen Artes y Educación). Facultad de Bellas Artes de Barcelona, Universitat de Barcelona, Barcelona.

CASTRO, Alice Viveiros de. (2005) O elogio da bobagem: palhaços no Brasil e no mundo.1 ${ }^{\mathrm{a}}$ edição. Rio de Janeiro: Editora Família Bastos. 
CORDEIRO, Karla. (2017). "Palhaçaria feminina: trajetória de investigação e construção dramatúrgica de espetáculos dirigidos por Karla Koncá”. In: SEMINÁRIO INTERNACIONAL FAZENDO GÊNERO 11 \& 13 th WOMEN'S WORLDS CONGRESS. Florianópolis. Disponível em <http://www.wwc2017.eventos.dype.com.br/resources/ anais/1503793078_ARQUIVO_7688911.pdf> Acesso em 31/o7/2018.

DEL PRIORE, Mary. (200o). Corpo a Corpo com a mulher - Pequena Historia das Transformações do Corpo Feminino no Brasil.1aedição. São Paulo: EditoraSenac.

DOLAN, Jill. (1990). “ 'Lesbian' Subjectivity in Realism: Dragging at the Margins of Structure and Ideology".In CASE, Sue-Ellen.Performing Feminisms: Feminist Critical Theory and Theatre. United States: The Johns Hopkins University Press. p. 40-53.

FLORES, Andréa Bentes. (2014). Palhaçaria Feminina na Amazônia Brasileira: uma cartografia de subversões poéticas e cômicas. Dissertação (Mestrado em Artes). Instituto de Ciências da Arte, Universidade Federal do Pará, Belém.

JUNQUEIRA, Mariana Rabelo. (2012). Da graça ao riso: contribuições de uma palhaça sobre a palhaçaria feminina. Dissertação (Mestrado em Teatro). UniversidadeFederal do Estado do Rio de Janeiro. Rio de Janeiro.

KASPER, Kátia Maria. (2004). Experimentações clownescas: os palhaços e a criação de possibilidades de vida. Tese (Doutorado em Artes da Cena). Universidade Estadual de Campinas, Faculdade de Educação. Campinas.

MERLEAU-PONTY, Maurice. (1945). Phénoménologie de laperception.1a Edição. Paris: Gallimard.

MIRANDA, Maria Brígida de. (2008). "Rainhas, sutiãs queimados e bruxas contemporâneas: reflexões a partir da montagem de Vinegar Tom”. Urdimento Revista de Estudos em Artes Cênicasda Universidade do Estado de Santa Catarina, n. 11, 2: p.133-146, set-dez.

MINOIS, Georges. (2003). História do riso e do escárnio.3ำ edição. São Paulo: Editora da Universidade do Estado de São Paulo (UNESP).

MONTEAH, Sara. (2014). Mulheres Palhaças: percursos históricos da palhaçaria feminina no Brasil. Dissertação (Mestrado em Artes). Instituto de Artes, UNESP, São Paulo. 
NASCIMENTO, Maria do. (2017). Olha a palhaça no meio da praça: LilyCurcio, Lilian Moraes, questões de gênero, comicidade e muito mais!.Dissertação (Mestrado em Artes). Instituto de Artes, UNESP, São Paulo.

RAME, Franca. (2004). A mulher-palhaço, a bufa, a jogralesa. In: FO, Dario. (2004). Manual mínimo do ator.za edição. São Paulo: Editora Senac.

RAMINELLI, Ronald (2008). “Eva Tupinambá”. In: DEL PRIORI, Mary. (2008). História das Mulheres no Brasil. São Paulo: Contexto.p. 11-44.

REMY, Tristan. (1945). Les Clowns.1a edição. Paris: Grasset\&Fasquelle.

Recebido: 23.09.2018

Aceito: $17 \cdot 10.2018$ 